\title{
European Tobacco Product Directive: How to address characterizing flavors as a matter of attractiveness?
}

\author{
Frank Henkler $^{1} \cdot$ Andreas Luch $^{1}$
}

Received: 17 June 2015 / Accepted: 22 June 2015 / Published online: 3 July 2015

(C) Springer-Verlag Berlin Heidelberg 2015

The European Tobacco Product Directive was finally adopted by the European Parliament and the European Council on April 3, 2014 (EU 2014). As often in European legislation, middle grounds were required to be reached to balance for harmonized trade and standards of health and consumer protection, which may differ between various member states. Some important issues have been successfully addressed though. Importantly, combined health warnings that include text and pictures will become mandatory to illustrate the deleterious effects of tobacco smoke on unborn children, certain organs or human health in general. Reporting obligations by manufacturers will now be strengthened, and products need to carry unique identifiers that enable to track the product flow from manufacturers to the first retail outlet. The new European Directive will also address some issues related to electronic (e-) cigarettes, including nicotine contents of cartridges, refill bottles and disposable products. Although the directive provides major improvements in some fields of consumer health protection, a new paradigm was introduced and finally adopted in order to regulate constituents, ingredients and emissions. The currently still applicable European Directive 2001/37/ EU was aimed at authorizing additives in tobacco products (EU 2001). The European Commission was obliged to draft a common list of authorized additives by December 31,2004, but failed to comply with this obligation ever since. From the perspective of consumer health protection, a clear and well-founded white list of acceptable additional

Andreas Luch

Andreas.Luch@bfr.bund.de

1 Department of Chemical and Product Safety, German Federal Institute for Risk Assessment (BfR), Max-Dohrn-Strasse 8-10, 10589 Berlin, Germany ingredients is highly desirable, since it would reduce the likelihood of using poorly characterized compounds that might pose additional toxicological risks, especially when being inhaled. An authorization system can also prevent proliferation of innovative products, possibly adapted to new-fashioned expectations of next-generation smokers. Conversely, the revised directive only requires the notification of novel products in advance of marketing. Notwithstanding, it becomes increasingly difficult to predict future products on the European market due to unleashed ingenuity and creativity in a globalized world. Some "modified risk products" will probably fall into this innovation hutch, and it also appears feasible to promote, for example, creams, suppositories or inhalers as novel products, provided they contain tobacco, any kind of processed tobacco or even tobacco extracts only. Unfortunately, this novel but kind of lax approach to regulating tobacco additives via notification and prohibitions of selected compounds can be viewed as backfall when compared to the former authorization concept, as drafted in the previous directive. Moreover, member states will lose their freedom to implement more stringent rules with regard to manufacture, import, sale and consumption of tobacco products, which they might deem necessary to protect public health (2001/34/EU, Article 13).

One principle achievement of the revised Tobacco Product Directive was to transfer important measures of the WHO Framework Convention on Tobacco Control (FCTC) into European law. FCTC is an international treaty that was 


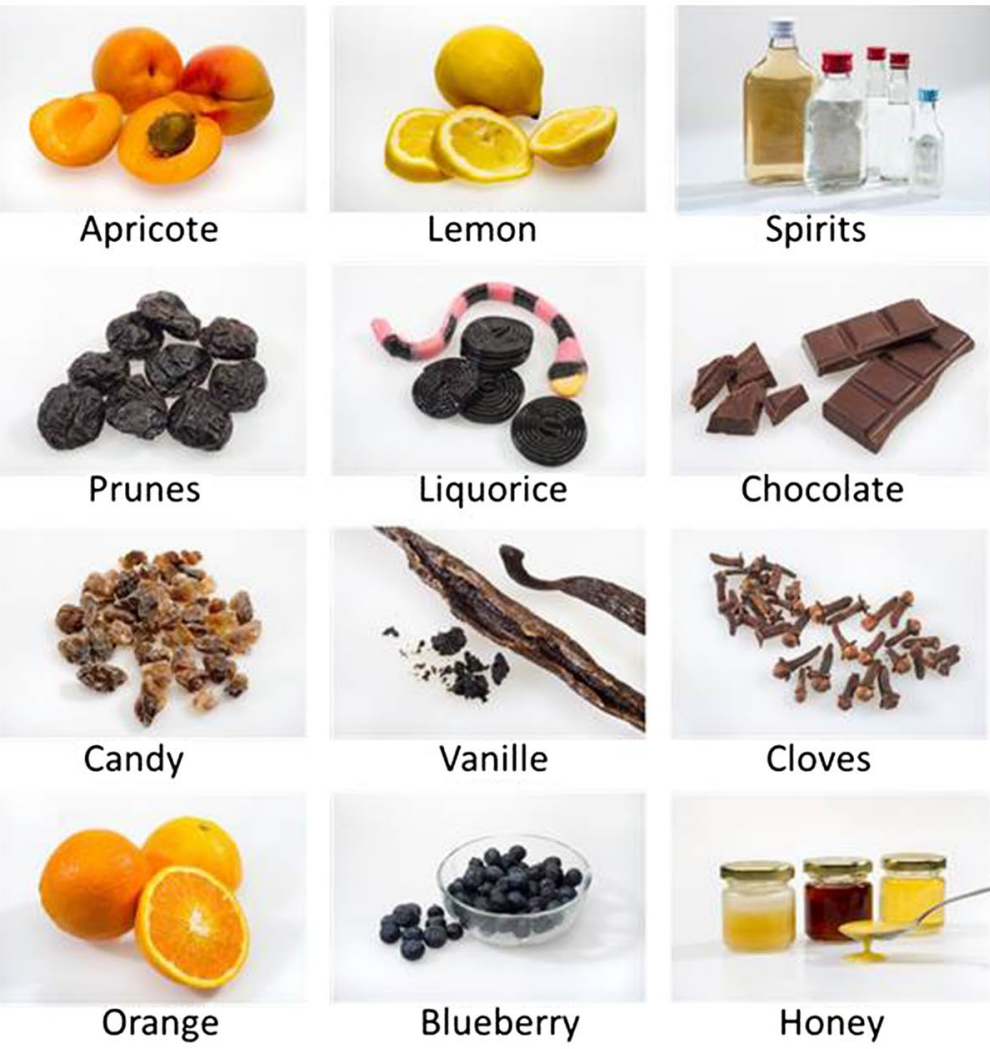

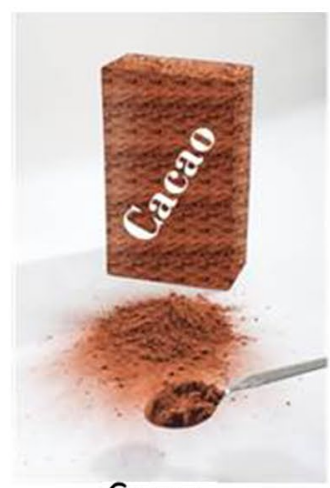

Cacao

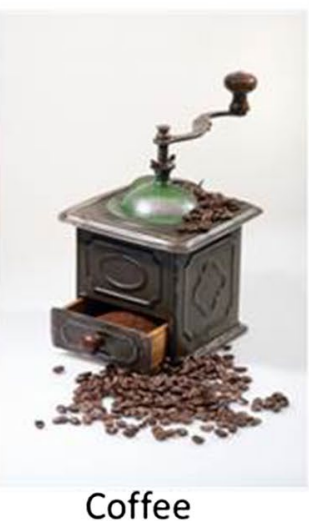

Coffee

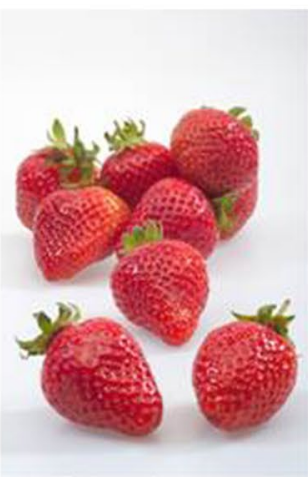

Strawberry

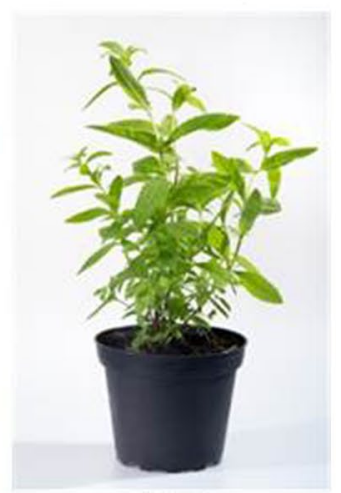

Mint

*Image courtesy of Günter Friedmann-Marohn (BfR)

Fig. 1 Flavors used in tobacco products (selection)

negotiated and finally adopted in 2005 as result of an initiative of WHO (http://www.who.int/fctc/en/). ${ }^{1}$ By May 2011, the FCTC was ratified by 171 countries, including all EU member states, as well as the European Union. ${ }^{2}$ The mandatory but rather generally worded obligation of article 9 to regulate constituents and additives of tobacco products has subsequently been worked out by the FCTC parties and specified in the partial guidelines that are meant to assist implementation. Importantly, the partial guideline to articles 9 and 10 is recommending prohibitions or restrictions for ingredients that are likely to enhance the attractiveness of tobacco products. Explicitly, this also comprises flavors that may increase product's palatability. According to the guidelines, flavors can reduce the harsh and irritating character of tobacco smoke and, hence, assist in early stages of experimentation until the possible onset of addiction. However, no precise measures have yet been specified in the

\footnotetext{
${ }^{1}$ WHO Framework Convention on Tobacco Control, adopted May 21, 2003, 2302, U.N.T.S. 166 (entered into force February 27, 2005).

2 http://www.dkfz.de/de/tabakkontrolle/download/Publikationen/ sonstVeroeffentlichungen/Das_Rahmenuebereinkommen_der_WHO_ zur_Eindaemmung_des_Tabakgebrauchs_FCTC.pdf.
}

FCTC provisions or its accompanying guidelines of how to restrict the multitude of different kinds of flavors that could be possibly applied in the furnishing of tobacco products.

At the international level, in the following different options had been chosen and implemented into national laws (Mitchell and Voon 2012). In Canada, for instance, all additives that have flavoring properties or that enhance product's flavor have been prohibited in 2009 by the "Cracking Down on Tobacco Marketing Aimed at Youth Act." 3 This regulation is considering the intrinsic properties of additives, rather than real sensory effects before or during smoking. Individually different kinds of perception or other subjective measures have therefore been excluded from affecting regulation. According to the Canadian approach, a flavor in general becomes prohibited, even so when it remains imperceptible in the finished product (Mitchell and Voon 2012). However, there are some exemptions, including menthol, which is still permitted in Canada.

\footnotetext{
${ }^{3}$ http://laws.justice.gc.ca/eng/AnnualStatutes/2009_27/page-5. html\#docCont, schedule that contains the list of prohibited additives in Canada.
} 
Fig. 2 Is there any measurable contribution of additives to the toxicity of tobacco products?

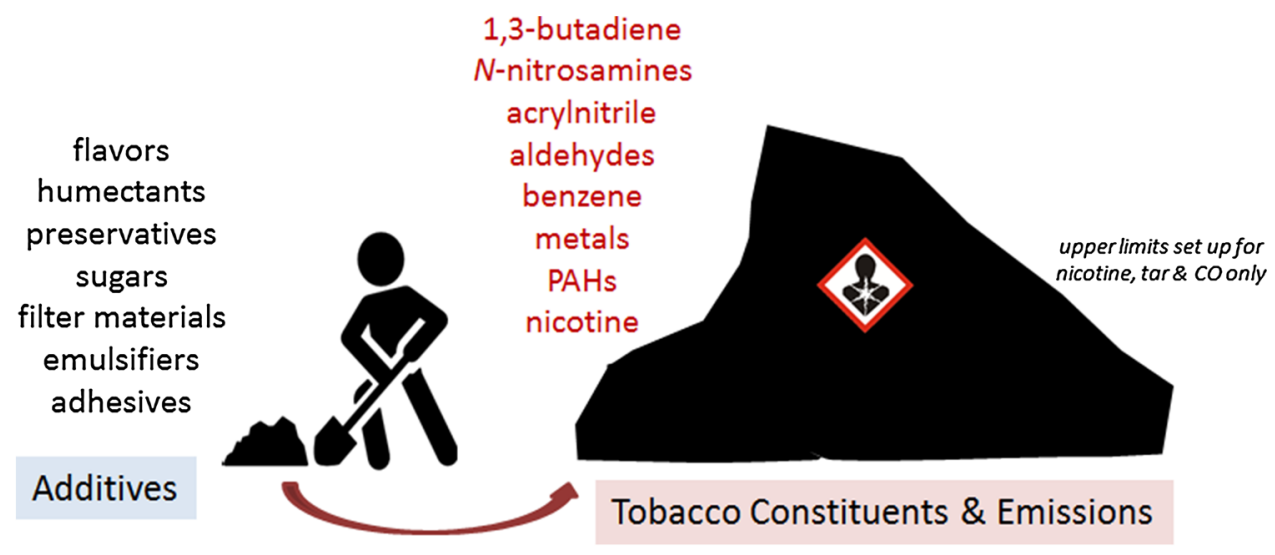

*Icon made by Freepik from www.flaticon.com (http://www.flaticon.com/free-icon/worker-with-shovel_62770)
A less stringent paradigm was adopted in the USA. According to the "Family Smoking Prevention and Tobacco Control Act," only characterizing flavors have been prohibited since 2009. ${ }^{4}$ However, flavors and aroma compounds can still be added to cigarettes, as long as the overall flavor does not attain characterizing properties. This far less rigorous approach does still allow manufacturers to differentiate and advertise product brands according to their taste. Although characterizing flavors are not specifically defined in the act, numerous examples, including strawberry, grape, orange, cocoa or chocolate, are given (Fig. 1). Notably, mentholated cigarettes, which maintain a much higher market share in the USA when compared to Canada or Germany, are also exempted. The USA never ratified the FCTC and therefore is not obliged to its implementation though.

The European Commission did follow the less stringent US approach when the revised directive was drafted in 2012. With respect to the lowering of product attractiveness, restricting characterizing flavors must be regarded as basic strategy aiming to introduce just minimum standards as set by the WHO FCTC. Nevertheless, the Commission did succeed to implement a common strategy toward the FCTC, thus preventing a pending fragmentation of the European tobacco market. Overall, this strategy might be justified, the more so as particular flavors that are especially relevant for adolescent non-smokers will be covered by the directive. Unfortunately, the definition of what means "characterizing" flavor remains inappropriate and unclear because the European directive only refers to a clearly noticeable smell or taste, distinguishable from that of natural tobacco. This definition does certainly invite for interpretation. Several questions might be raised. Some examples:

- Can a taste be regarded as characterizing, when it can be distinguished by some consumers from other aroma compounds, without masking a dominant tobacco taste?

\footnotetext{
${ }^{4}$ http://www.fda.gov/TobaccoProducts/GuidanceComplianceRegulatoryInformation/ucm237092.htm.
}

- Can a taste be regarded as characterizing without recognizable associations with non-tobacco products or other commodities?

- Is a vague somehow fruity but clearly noticeable sensory impression already sufficient to claim characterizing properties?

Given these considerations, a clear distinction between acceptable flavors admissible of being present in tobacco products and such prohibited "characterizing flavors" certainly will become challenging for European regulators and surveillance authorities. Although the Commission may lay down uniform rules and establish an independent advisory panel, no further ideas and concepts have been discussed yet. Maybe maximum values can be introduced for flavors that depend on only one or very few aroma compounds, for example vanilla or clove. On the other side, it will be far more difficult to relate complex flavors, such as strawberry, cherry or mango, to defined synthetic or natural aroma compounds. Most likely product surveillance will mainly depend on sensory tests, but this certainly should be assisted and backed up — wherever possible — by reproducible chemical analysis in order to introduce objective and reliable scientific criteria. For such an analytical approach, however, detailed analyses of flavor constituents and compositions that are currently used in tobacco products will be necessary. The data obtained could then be used for an initial screening of annual reports that must be provided by manufacturers or importers for all tobacco products on the European market. Since surveillance authorities might be flooded with data for every single product, an automatic preselection would be desirable to earmark products that are possibly associated with characterizing flavors. Further, conspicuous products on the market should be documented by surveillance authorities to assure equal assessment criteria. Again this would require identification of one or more specific chemical marker compounds sufficient to indicate the presence of a certain characterizing flavor. 
The feasibility of this strategy was explored in the study authored by Paschke et al., using strawberry flavor as an example. According to the data presented in this issue of Archives of Toxicology, signatures of aroma compounds are well be suitable to monitor characterizing flavors, which are even distinguishable from other fruity tastes. Clarifications by sensory testing might still be necessary at some point, but certainly could be limited to a rather low number of preselected samples.

The attempt to regulate characterizing flavors is going to shift the European focus to the restriction of the palatability as major part influencing the attractiveness of tobacco products. On the other side, prohibitions based on an increased toxicity or addictiveness will hardly be possible, because such effects need to be significant and measureable in the finished products ready for consumption (2014/40/ EU, article 7, \#9). In view of the extremely high toxicity and addictiveness of pyrolyzed tobacco as such, it would be more than challenging not to say impossible to prove comparatively minor health effects added on top of it by the application of certain additives (Fig. 2). Importantly, it remains to be clarified whether additives that might trigger novel risks which are usually not associated with tobacco products, should be regulated under these provisions. One important example is diacetyl (i.e., butane-2,3-dione), a flavor that can trigger certain respiratory diseases (e.g., bronchiolitis obliterans) when being inhaled (Kreiss et al. 2002; Morgan et al. 2008, 2012). Yet, until now there are no such studies for tobacco products available which could prove or exclude measureable effects at the stage of consumption. In these cases, the Canadian approach to restricting additives according to their intrinsic and health-related properties appears to be far more sensible and straightforward. A second example is menthol. Although its characterizing peppermint-like taste will be prohibited in cigarettes and "roll-your-own" tobacco, menthol might still be added at lower concentrations that contribute to mask the airway irritation properties of cigarette smoke. This effect is primarily triggered via activation of the cold-sensing receptor TRPM8 and known to be mostly independent from taste (McKemy et al. 2002; Kamatou et al. 2013; Millqvist et al. 2013). From the perspective of risk assessment, concerns on intrinsic toxicological properties, as well as recognized physiological effects of constituents and additives, should be further addressed and strengthened in the regulation of cigarettes and other tobacco products .

\section{References}

EU (2001) Directive 2001/37/EU of the European Parliament and of the Council of 5 June 2001 on the approximation of the laws, regulation and administrative provisions of the member states concerning the manufacture, presentation and sale of tobacco products

EU (2014) Directive 2014/40/EU of the European Parliament and of the Council of 3 April 2014 on the approximation of the laws, regulation and administrative provisions of the member states concerning the manufacture, presentation and sale of tobacco and related products and repealing Directive 2001/37/EC

Kamatou GP, Vermaak I, Viljoen AM, Lawrence BM (2013) Menthol: a simple monoterpene with remarkable biological properties. Phytochemistry 96:15-25

Kreiss K, Gomaa A, Kullman G, Fedan K, Simoes EJ, Enright PL (2002) Clinical bronchiolitis obliterans in workers at a microwave-popcorn plant. N Engl J Med 347:330-338

McKemy DD, Neuhausser WM, Julius D (2002) Identification of a cold receptor reveals a general role for TRP channels in thermosensation. Nature 416:52-58

Millqvist E, Ternesten-Hasseus E, Bende M (2013) Inhalation of menthol reduces capsaicin cough sensitivity and influences inspiratory flows in chronic cough. Respir Med 107:433-438

Mitchell A, Voon T (2012) Regulating tobacco flavors: implications of the WTO law. Boston Univ Int Law J 29:383-425

Morgan DL, Flake GP, Kirby PJ, Palmer SM (2008) Respiratory toxicity of diacetyl in C57BL/6 mice. Toxicol Sci 103:169-180

Morgan DL, Jokinen MP, Price HC, Gwinn WM, Palmer SM, Flake GP (2012) Bronchial and bronchiolar fibrosis in rats exposed to 2,3-pentanedione vapors: implications for bronchiolitis obliterans in humans. Toxicol Pathol 40:448-465 